\begin{abstract}
No. 4143 March 26, 1949
Anclent Pottery of the Near East

Pottery sherds, why they occur, are some of the most useful 'f $\mathrm{ssils}$ ' 1 prehistorian can have to deal with. When het are found with an industry, one can be almost ertain that they are contemporary. It follows then, that a known ware imported from som Wistant region and found associated with an unkn pwn industry will date that industry with reasonable accuracy as being contemporary with the culture which manufactured the particular ware in question. This is not so true in the case of beads. It is a fact, of course, that when the association is real and there has been no subsequent chance introduction, the industry with which the bead of known date is found must be either contemporary with it or later in date. But beads have a long survival value; necklaces made of Egyptian beads were popular in late Victorian times, thousands of years after they were made. Prehistoric housewives, however, smashed crockery as freely as their descendants, and the survival value of a pottery vessel in use is limited. Pottery, then, is particularly useful for correlating in time various cultural levels from different regions. We can therefore be grateful to Marian Welker, who in a paper entitled "The Painted Pottery of the Near East in the Second Millenium B.c. and its Chronological Background", has brought together in convenient form a wealth of detail of the pottery in the Near East at this period (Trans. Amer. Phil. Soc., N.S., 38, part 2 ; September 1948). The paper is arranged by sites and areas, considering especially a number of Syrian localities. The author considers that Mesopotamian influence on the development of the wares in these sites is sporadic and that we shall have to look rather to an Iranian cradle for their origin. Chronological tables and some pages of illustrations are included, and the resulting volume will certainly prove of great use to students. There are also a catalogue of forms and several pages of references.
\end{abstract}

\section{Society of Public Analysts and Other Analytical Chemists}

THE seventy-fifth annual general meeting of the society was held on March 9 in the meeting room of the Royal Society, Burlington House, London, W.1, with the retiring president, Mir. Lewis Eynon, in the chair. In b/s address, Mr. Eynon began by remarking on the Speiety's membership of 1,500 , a doubling of the figyre of ten years ago; he announced that, in alteryate years in which no change of president occlrs, the lecture which is delivered at the annual general meeting will in future be known as the Bernard Dyer Memorial Lecture, in honour of the late Dr. Bernard Dyer. The main theme of Mr. Eynon's address was the fundamental importance of analysis to the progress of chemistry and the necessity for giving a prominent place to analysis in the training of the student of chemistry. He said that although two former presidents of the Society had both deplored the inadequacy of training in analytical chemistry, little advance has been made in the status of analysis as a subject of instruction in the universities and technical colleges of Great Britain ; indeed, the position has if anything become worse owing to the increasing claims of other branches of the science on a student's time. The great utilitarian value of training in analysis is too obvious and manifold when one considers its application to industry, medicine, water supply and Government inspection.
The most important practicable step is for the establishment of chairs of analytical chemistry in universities and colleges and for a longer period of training for the student. With the present unsatisfactory conditions of training there is a serious danger that within the next twenty years the analyst himself will be "weighed in the balance and found wanting".

The following officers and members of Council were elected for the ensuing year: President, George Taylor; Past Presidents serving on the Council, F. W. F. Arnaud, Lewis Eynon, E. B. Hughes, G. Roche Lynch, S. E. Melling, G. W. MonierWilliams; Vice-Presidents, C. A. Adams, H. E. Cox, J. R. Nicholls, J. G. Sherratt (chairman, North of England Section), J. Sword (chairman, Scottish Section); Honorary Treasurer, J. H. Hamence; Honorary Secretary, K. A. Williams; Other Members of Council, N. L. Allport, R. C. Chirnside, J. F. Clark, D. C. Garratt, J. G. A. Griffiths, E. T. Illing, J. King, J. E. Page, C. J. Regan, F. A. Robinson, N. Strafford, A. M. Ward, A. Lees (honorary secretary, North of England Section), R. S. Watson (honorary secretary, Scottish Section).

\section{New Grassland Research Station at Hurley, Berks}

A New Grass/and Research Station for Great Britain is being established by the Minister of Agriculture and he Secretary of State for Scotland in co-operatign with the Agricultural Research Council. The ney Station will occupy an area of 500 acres at Hycley, Berkshire, adjoining the new Berkshire Fary Institute. Its work will be the investigation of problems relating to the sward and its production and maintenance under different conditions, but mainly under those of medium and low rainfall. The existing Grassland Improvement Station at Drayton, Stratford-on-Avon, will be transferred to and amalgamated with the new Station. The work at Hurley will be carried out in close co-operation with that of the Welsh Plant Breeding Station at Aberystwyth, the Scottish Society for Research in Plant Breeding and other research institutions, and it will be under the scientific supervision of the Agricultural Research Council. The Station will be controlled by a Governing Body which will be constituted as a company limited by guarantee and without share capital, grant-aid being given by the Ministry of Agriculture. The thirteen members who have been appointed to the Governing Body, and of which Prof. H. G. Sanders is chairman, provide a balanced representation of scientific knowledge and practical farming experience.

\section{Liquid Helium-3}

IN the Physical Review of January 15, p. 303, S. G. Sydoriak J.R. Grilly and E. F. Hamel report that on Octeber 13, 1948, they succeeded in condensing $p$ o helium-3. This is especially interesting, since fseral physicists, F. London, Tisza, and others, hqve Expressed doubts that helium-3 would liquefy. Tdenty c.c. (measured at S.T.P.) of helium-3 were used, and condensation took place at the bottom of a $1 \cdot 2-\mathrm{mm}$. bore stainless steel capillary immersed at a depth of $5-10 \mathrm{~mm}$. in the liquid helium well. Condensation was assumed to be taking place when the equilibrium pressure in the capillary was independent of the volume of helium which remained in the mercury manometer connected to the roomtemperature end of the capillary. From the data obtained, $3 \cdot 3_{4}{ }^{\circ} \mathrm{K}$. was chosen as the critical temperature of helium-3. The vapour pressure measure- 
ments showed that at $1 \cdot 2^{\circ} \mathrm{K}$. the vapour pressure of helium-3 was thirty-five times that of helium-4; helium-3 was suitable for thermometry at low temperatures down to $0.5^{\circ} \mathrm{K}$. and perhaps lower; the normal boiling point of helium-3 was $3 \cdot 2^{\circ} \mathrm{K}$., and by extrapolation to the critical temperature the critical pressure was $875 \mathrm{~mm}$. of mercury. A value of $0: 04 \mathrm{l} \mathrm{gm} . / \mathrm{c} . c$. for the critical density was deduced. Birds in London

IN April 1947 thenister of Works appointed a Committee on Bi d Sanctuaries in the Royal Parks (England and ales). For its general objectives the Committee peided to: (1) make suggestions for increasiply the resident population of birds, their nuy berl and variety; (2) make suggestions for at racting migratory birds and for inducing unusual visitors to stay longer; (3) select competent persons as observers and reporters.

The Committee has now reported, and the results of its deliberations have been set out in a pamphlet, "Birds in London" (H.M. Stationery Office. 9d.). The first duty was the appointment and guidance of competent observers, and it is their statements which provide most of the material in the pamphlet. They show how successful has been the policy of developing the London bird sanctuaries, which were originally soyp so long ago as 1923.

\section{Youhg Children}

To mark the $y$ of its silver jubilee, the Nursery School Assqgiation of Great Britain has begun the publication da new quarterly journal. This follows the form tion of the World Council of Early Childhood. Edvcation after an international meeting in Prque, in August 1948, and the new journal is interled to act as a link between all who are interested in the education of young children in any part of the world. Volume I of Young Children contains articles on the use of water play in the nursery, the stages of education which follow the nursery school and the links between home and school. The new journal has been produced unpretensively and should strengthen a side of education which has been much neglected by existing journals. It is doubtful, however, if the new journal will survive unless the price is reduced.

\section{Hundredth Meeting of the Genetical Society}

THE Genetical Society of Great Britain, founded in 1919 by W/liam Bateson, will hold its hundredth meeting daring June 30-July 1, in Cambridge. To mark the occasion guest speakers will review the early gays of genetics, and there will also be comprehonsive demonstrations of genetical work now in prggress in Great Britain. Genetical societies abroad bave been informed of this meeting, to which all geneticists are cordially invited. Details may be obtained from the secretaries, G. Pontecorvo, Department of Genetics, University, Glasgow, W.2, or H. G. Callan, Institute of Animal Genetics, Unizgrsity, Edinburgh 9.

The Night Sky in April

FuLl moon occurs on April 13d. 04h. 08m., U.T., and new moon on Aptily $28 \mathrm{~d} .08 \mathrm{~h} .02 \mathrm{~m}$. The following conjunctits with he moon take place: April $9 \mathrm{~d}$ 13h., Naturn $3^{\circ} \sigma . ;$ April 20d.03h., Jupiter $5^{\circ} \mathrm{N}$.; A rry 29d. 2lb Mercury $0.7^{\circ} \mathrm{S}$. Mercury is in supenr conf iction on April 13 and is not favourably placed for observation until later in the month; the planet sets 1h. 45m. after the sun on April 30, and can be seen in the western sky. Venus, in superior conjunction on April 16, is too close to the sun for favourable observation throughout the month. Mars rises about the same time as the sun during April, and cannot be observed. Jupiter is a morning star, rising at $3 \mathrm{~h} .20 \mathrm{~m}$. , 2h. $30 \mathrm{~m}$. and $1 \mathrm{~h}$. $35 \mathrm{~m}$., at the beginning, middle and end of the month, respectively, and can be seen low down for a few hours before sunrise. Saturn sets in the early morning hours and is visible throughout the greater part of the night. Occultations of stars brighter than magnitude 6 are as follows: April 1d. 19h. $463 \mathrm{~m} ., 45$ Arie. $(D)$; April 7d. 00h. 31.4m., c Gemi. $(D)$; April 11d. 20h. $56 \cdot 3 \mathrm{~m}$., $\eta$ Virg. $(D) . \quad D$ refers to disappearance, and the latitude of Greenwich is assumed. The Lyrid meteor shower is active about April 18-24. A total eclipse of the moon, visible at Greenwich, takes place on April 13, the circumstances of which are given as follows: moon enters penumbra, 0lh. $31 \cdot 6 \mathrm{~m}$.; enters umbra, 02h. $27 \cdot 7 \mathrm{~m}$.; total eclipse begins, $03 \mathrm{~h} .28 \cdot 0 \mathrm{~m}$. ; middle of eclipse, 04h. $10 \cdot 9 \mathrm{~m}$; ; total eclipse ends, $04 \mathrm{~h} .53 .8 \mathrm{~m}$.; moon leaves umbra, $05 \mathrm{~h}$. $54 \cdot \mathrm{Im}$.; leaves penumbra, $06 \mathrm{~h} .50 \cdot 3 \mathrm{~m}$. A partial eclipse of the sun, visible at Greenwich, occurs on April 28, its magnitude being 0.41 at Greenwich, where it begins at $6 \mathrm{~h} .21 \mathrm{~m}$., reaches its greatest phase at $7 \mathrm{~h} .15 \mathrm{~m}$., and ends at $8 \mathrm{~h} .14 \mathrm{~m}$.

\section{Announcements}

ON the joint recommendation of the presidents of the Royg Society and the Institution of Civil Engineefs, the Council of the Institution of Civil Engincers has awarded the James Alfred Ewing Medal for 1948 to Sir Edward Appleton. The medal is awarded annually, and was founded in 1936 in memory of Sir Alfred Ewing. This award has come appropriately when Sir Edward has just taken up his appointment as vice-chancellor of the University of Edinburgh, a position which Sir Alfred Ewing occupied with such distinction.

DR. R. P. LINSTEAD, director of the Chemical Researh Laboratory, Teddington, since 1945, has accepted the invitation of the University of London to succeed Sir Ian Heilbron as professor of organic chemistry and director of the Organic Chemistry Laboratories at the Imperial College of Science and Technology as from April 1, or as soon afterwards as can be arranged.

M. Guston Dupoux has been elected correspondant for the Section of General Physics of the Paris Acdemy of Sciences in succession to Prof. W. J. de Haas, who has been elected a foreign associate.

A DIvision of the Royal Aeronautical Society has recently been formed in South Africa on the same lines those formed in Australia and New Zealand in Otober 1948. Associate fellows will still be elected by the parent body of the Society in London; but otherwise these Divisions of the Commonwealth will possess a fully self-governing status and will be free to develop along their own national lines.

THE Royal Photographic Society will be holding its annual exhibition at 16 Princes Gate, London, S.W.F, in two parts : part 1 (pictorial and colour), September 9-October 2; part 2 (scientific, Nature, medical, record, press, commercial, industrial, techfical and radiographic), October 8-26. Admission will be free. Entries must be received by July 23 , and entry forms may be obtained from the Secretary at the above address. 